\title{
Industry-University Collaboration, A University of Dayton Model
}

\author{
Guru Subramanyam \\ Department of Electrical and Computer Engineering University of Dayton \\ 300 College Park, Dayton, OH 45469 \\ gsubramanyam1@udayton.edu
}

\begin{abstract}
This paper introduces industryuniversity collaboration activities currently in place at the University of Dayton's School of Engineering. These collaborations are important to prepare industry-ready graduates who excel in technical, entrepreneurial, and leadership skills. One of the key curricular component is the industry sponsored multidisciplinary projects. Industry involvement in advisory committee, strategic research partnerships, and other forms are discussed.
\end{abstract}

Keywords- industry ready graduates, industryuniversity collaborations, industry sponsored projects, innovation center, engineering graduates.

\section{Guru Subramanyam}

Department of Electrical and Computer Engineering

University of Dayton

300 College Park, Dayton, OH 45469

gsubramanyam1@udayton.edu

\section{Introduction}

University of Dayton (UD) is a private, Catholic University, founded by the Society of Mary in 1850. The engineering programs were started in 1911 as a natural outgrowth of physical sciences in what used to be called as the St. Mary's College. Electrical Engineering and Chemical Engineering were the first programs that were started in 1911, followed by Mechanical and Civil Engineering a few years later. From the beginning, the focus of the programs were to prepare industry-ready graduates. Dayton was a hub for innovation as Wright Brothers developed their first powered flight at the Wright field. Charles Kettering invented the ignition system that launched the Dayton Engineering Laboratories Company (Delco). National Cash Register (NCR) led the development of calculators and early computers. With Wright Patterson Air Force Base nearby, it didn't take too long for faculty and students to be working on research projects for the Air Force. In 1949, a Marianist priest and a Mathematics professor, John Westerheide, at the University of Dayton saw an Air Force request for research assistance as an opportunity to play a role in America's postwar reconversion economy - as well as to provide new opportunities for faculty and jobs for students paying their way through school [1]. Three years later, UD hired five full-time researchers to support its growing number of contracts - a bold move for a small Midwest Catholic university focused on undergraduate teaching - and in 1956, with 20 sponsored projects underway, the need for a centralized research organization became clear[1]. 
On Sept. 1, 1956, the University of Dayton Research Institute (UDRI) was born and, after almost 60 years, it has emerged as a globally recognized leader in research and development of technologies that have advanced science and benefited mankind. Sponsored research has grown from $\$ 1$ million from 20-plus contracts in 1956 to more than $\$ 90$ million from $1,000+$ contracts in 2015; cumulative research revenue topped the \$1-billion mark in 2003[1]. This is especially significant in that UDRI, its research and its $400+$ engineers, scientists and support staff, are funded solely by contracts and grants from external customers, including industry, department of defense, national science foundation, NASA, etc.

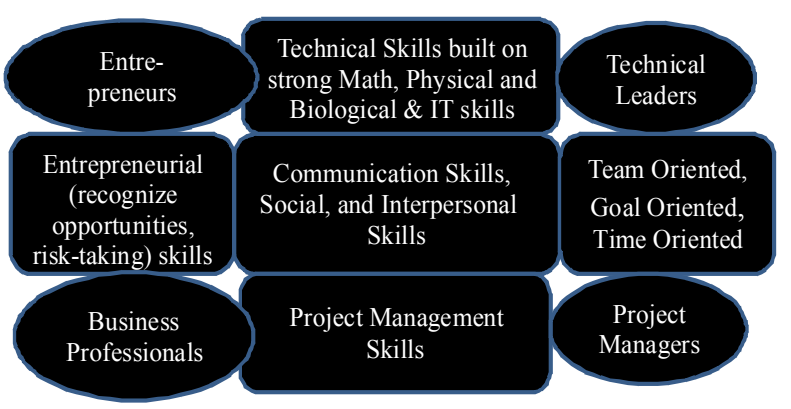

Figure 1. Options for engineering careers with key skills necessary for each option.

\section{Preparing Industry-ready Graduates}

All engineers require strong communication, social, and interpersonal skills. Engineers can choose to become entrepreneurs, tech leaders, project managers, and business professionals. The project managers will need to be team, goal and time oriented with excellent project management skills. Both tech leaders and project managers need to be team oriented, goal oriented and time oriented. Technical leaders will have strong technical skills built on math, sciences and information technology foundations. The science foundation will need to have both physical sciences (physics and chemistry) and biological sciences. Business professionals need to have good project management skills as well as entrepreneurial skills. Entrepreneurs need to have strong technical skills as well as entrepreneurial skills. Figure 1 summarizes the skills necessary for preparing students for successful careers.

\section{Curriculum Integrating Industry Projects}

Our curriculum has multiple components including an integrated engineering core (IEC), Mathematics and Science courses, Major core courses which include laboratory courses, major Electives, and Common Academic Program (CAP) courses. The IEC includes a first year engineering innovation course ( 2 credit hours) that introduces hands-on project based learning. The core courses include two experiential learning laboratory courses (ECE/MEE 431L ( 2 credit hours) \& 432L ( 3 credit hours)) in the senior year which are based on industry sponsored projects. Both these courses are conducted in the Innovation Center in the School of Engineering. More than $75 \%$ of projects are proposed and funded by industry sponsors or local entrepreneurs. Faculty and staff of UD and UDRI can also propose and run projects through the Innovation Center. A project in the 2 credit hours ECE/MEE 431L (Multidisciplinary Design I) course involves conceptualization, and costs $\$ 1500$ for an industry sponsor. Many of the projects from the 2 credit hours course transitions to the 3 credit hours ECE/MEE 432L (Multidisciplinary Design II) course, where prototype development takes place. The 3 credit hours course project costs a sponsor $\$ 4000$.

In 2013-14 academic year, we crossed a major milestone of 1000 projects, and 200 industry clients. The project sponsors include large companies such as GE, Boeing, Honda, Johnson \& Johnson, Emerson, BMW, and others. The sponsors include small companies and entrepreneurs as well. Emerson has topped the sponsor list with most number of projects over the years with over 70 in the past 15 years. Emerson also was instrumental in creating a state of the art prototype lab in the Innovation Center by donating over one million dollars. Advanced 3D printers, and $\mathrm{CNC}$ machines are available for student projects. In 2014-15 academic year alone, there were over 100 projects and 400 students participating in the capstone design projects. Each project has an assigned industry mentor apart from academic mentors. Students are expected to send at a minimum a status report on the project each week, and at least two oral presentation reviews prior to the end of the semester's final presentation and report to the sponsor. Benefits to the sponsor include: opportunity to address new product development, meaningful technical results, and new perspectives/concepts, innovative out of the box ideas, multi-disciplinary design team, UD and UDRI resources and facilities. Current projects that run through the Innovation Center cover a wide number of areas:

- Manufacturing, Facilities Layout, Ergonomics, 


\section{Six Sigma}

- Product Design, Structural Mechanics, Advanced Materials, Energy Systems, Rapid Prototyping

- Electrical Engineering, Computer Engineering, Digital Design, Mechatronics, Robotics

- Technical competitions such as Super-mileage car, Solar-splash, UAV, etc.

- Business Plans, Market Surveys, Focus Groups, Cost Estimating

It is worth noting that the intellectual property for the project outcomes are retained by the industry sponsor. There have been projects where students were included in patents for the projects run through the Innovation Center. Over the last 10 years, we have sought feedback from sponsors regarding the performance of student design teams. Two main categories that have been addressed include the significance of the results attained from the projects and the importance to the sponsoring organizations, as well as our measured success in achieving the goals and deliverables required from the projects. Sponsor surveys revealed that the goals set by the sponsors have been attained or exceeded in over $85 \%$ of the projects. The board of advisors for the Kern Entrepreneurship Engineering Network has designated the University of Dayton, School of Engineering as "Best in Class" in project based learning [2]. The industry funded multidisciplinary projects is a key factor in our very strong placement results (over 96\%) each year in the School of Engineering. Also, the Electrical \& Computer Engineering department was recently announced as the winner of the "Hidden Gem Index" award for Electrical and Communication Engineering, by the College Recruiter magazine [3]. The magazine surveys industries to identify hidden gem programsfor various disciplines of engineering.

\section{Industrial Advisory Board Participation In Strategic Planning}

In addition to curricular issues for preparing industry ready graduates, our department also has a very active industrial advisory committee (IAC). The IAC members represent wide range of industries from information technology to aviation power systems. Majority of the members are our own alumni giving back to their own alma mater. Many of them are in their top technical leadership positions within their organizations. The members also are involved in state of the art technologies and understand the trends of various industries. The IAC works closely with the department faculty and staff in the department's strategic planning, curricular analysis for both undergraduate and graduate programs, co-op and student leadership development. The IAC meets with the department faculty and staff once each semester at a minimum. The IAC has contributed to a curricular gap analysis, establishing centers of excellence in key areas, developing new innovative initiatives for students, and establishing department's metrics to become of one of the top programs in the country.

\section{Research Collaborations With Industry}

Faculty and staff undertake sponsored research projects from various companies based on their research areas. One of the mechanisms for this is subcontract work on Department of Defense (DOD) contracts with many of the defense contracting companies such as McCauley Brown, Northrop Grumman, Ball Aerospace, and others. While UDRI is a contract vehicle, some of the projects are undertaken through subcontracts. There are also collaborations with companies at the proposal stage for Small Business Innovative Research (SBIR), and Small Business Technology Transfer (STTR). These are joint proposals between universities and industry to the DOD. There are many such projects being carried out at UD and UDRI. There are also projects executed as direct contracts between industries and our department. Sony, TI, CISCO, Yashkawa Motoman Robotics Company, and L3 Communications, are some of the companies collaborating with our faculty in Electrical \& Computer Engineering department. In 2008, Yashkawa Motoman forged a research partnership with our department and created the Motoman Robotics Lab. The robotics lab houses six state of the art robots and controllers with total investment of close to \$1 Million. In 2014, the partnership with Yashkawa Motoman Company expanded as we worked closely with them to design a unique RF Tomography lab utilizing high precision robots that are capable of positioning $\mathrm{rf}$ transmitters and receivers down to $30 \mu \mathrm{m}$ precision. Four high precision robots are used to perform radar cross-section measurements, and RF tomography. It is one-of-akind lab named the Mumma Radar Lab, and is a playground for RF/microwave measurements [4]. Key Sight Technologies (a spin-off from Agilent 
Technologies) is a key partner for establishing the Mumma Radar Lab. We are also offering a new course on RF/Microwave lab for senior undergraduates and graduate students in collaboration with Key Sight Technologies. The top students with A grades will automatically get "Industry Ready $\mathrm{RF} /$ Microwave Engineer" certification from KeySight Inc.

\section{Establishing Centers Of Excellence Catering To Industry}

Led by the University of Dayton, the Institute for Development and Commercialization of Advanced Sensor Technologies (IDCAST) was established in 2008 through a \$28 million State of Ohio Third Frontier Grant. The mission and vision around IDCAST was started by the State of Ohio to support research and development to help Ohio companies continue to make progress toward being able to commercialize sensor related technologies. Today, IDCAST has over 30 companies and 8 universities as its partners making it one of the most prominent advanced sensor related research and development centers in the United States. They have provided support to 5 startups companies, financial assistance to 13 companies, created 280 jobs, and had an economic impact of over $\$ 140$ million for the State of Ohio[5]. Many of the projects of IDCAST are performed in collaboration with our department faculty, staff and students.

A second proposal to the Ohio Third Frontier program was to create a Ohio Academic Research Cluster for Layered Sensing. This grant allowed us to hire three Ohio Research Scholar Professors (ORSP) in the Department of ECE, which has resulted in developing three centers of excellence, with over $\$ 10$ Million invested in our department alone. One of the centers of excellence is in Computer Vision, led by Professor Vijayan Asari[6], another one in distributed sensing, which is called the Mumma Radar Lab led by Professor Michael Wicks[4], and the third one is the Ladar and Optical Communication Institute (LOCI) led by Professor Mikhail Vorontsov[7]. Each of the COEs offers unique capabilities. These new COEs have resulted in a huge surge of our research programs and more than doubled our undergraduate and graduate enrollment over the past 5 years.

Another new industry centric lab is currently being established in our ECE department, called the integrated microsystems lab, led by Professor Vamsy
Chodavarapu. Through this lab, we will be able to offer multi-project wafer processing of microelectromechanical systems (MEMS) devices in partnership with many of the pureplay MEMS foundries.

\section{Industry Research Centers On Campus}

In 2013, GE Aviation opened the \$53 million GE Aviation Electrical Power Integrated Systems Center (EPISCenter) on our campus, thanks to a partnership between University of Dayton and GE Aviation [8]. The EPISCenter is the headquarters for GE Aviation's Electrical Power Systems business. The EPISCenter allows University of Dayton researchers and students to work side by side with GE Aviation scientists and engineers to create new advanced electrical power technologies such as new power systems for aircraft, longer-range electric cars, and smarter utility power grids for more efficient delivery of electricity. In the Spring of 2015, GE Aviation approved a GE EPISCenter Professor in Aviation Electrical Power Systems in the department of Electrical and Computer Engineering. This new named professor will work closely with the GE EPISCenter and develop academic programs in Electrical Power Systems. The EPISCenter stands as a testament to what imagination and collaboration can accomplish. In the higher education landscape nationally and internationally, this innovative partnership is a model for the future.

In 2014, Emerson Climate Technologies broke ground to its new Helix Innovation Center on our campus. The Helix innovation center is set to open officially in October 2015. The Helix Center will house a 2000 square feet home inside which will serve as a working laboratory, enabling faster testing of the company's new innovations in comfort, energy savings, and connected home concepts. Emerson's residential module will be a fully functioning and furnished home with technologies and instrumentation in place to research the comfort and energy savings performance of these systems as well as connected home technologies [9]. This research center also brings unique opportunities for our faculty, staff and students in working closely with engineers and researchers in Emerson.

\section{Technology Licensing, And Incubation}

In addition to the above industry involvements, the UDRI Technology Partnerships Office protects and markets various intellectual property developed by 
faculty and staff. The licensing of various technologies has resulted in several new companies as well. Recently, Apple Inc., licensed several of our patents in rechargeable lithium battery technology. UD also has incubation space where a few new startup companies are co-located. Optonicus is a successful new start-up company that is developing optical components, co-located within the ElectroOptics graduate program. Midmark, a global manufacturer of health care products, equipment and software for diagnostics, moved its corporate headquarters to our campus in 2012.

\section{Conclusions}

The University of Dayton's unique industryuniversity collaboration models are discussed in this paper. Wide range of industry involvement in our academic curricula, multidisciplinary design projects, and research collaborations have resulted in outstanding industry-ready graduates.

\section{References}

[1] University of Dayton Research Institute History a va i 1 a ble in the we b s ite : http://www.udri.udayton.edu/AboutUDRI/Pages/ History.aspx.

[2] More information on Kern Entrepreneurial Engineering Network (KEEN) is available at http://www.keennetwork.org
[3] Latest information on 2015 Hidden Gem Index A w a r s a va i a ble a t : https://www.collegerecruiter.com/blog/2015/04/2 2/best-schools-for-employers-who-want-to-hiretop-students-now/

[4] For further information on Mumma Radar Lab, p le a s e visit the we bsite: https://udayton.edu/engineering/centers/radarlab/ index.php

[5] Further information on IDCASTis available at the website, www.idcast.com.

[6] For further information on UD Vision Lab, please vi s i t $\mathrm{h}$ e $\quad \mathrm{w}$ e b s i t e https:/udayton.edu/engineering/centers/vision_la b/index.php

[7] For further information on LOCI, please visit the websitehttps://udayton.edu/engineering/centers/1 adar_and_optical_communications_institute/inde x.php

[8] Information on GE EPISCenter available at: https://www.udayton.edu/lead/episcenter.php.

[9] Additional information on the Emerson Climate Technologies new Helix Innovation Center available at: http://www.emersonclimate.com/enus/About_Us/News/News_Releases/Pages/emers on-climate-technologies-constructing-modelhome-inside-research-center-to-study-comfortinnovations.aspx\#sthash.9eUKAQyL.dpuf 